\title{
LA LEY 9/2020, DE 31 DE JULIO, DE MODIFICACIÓN DEL LIBRO II DEL CÓDIGO CIVIL DE CATALUÑA Y DE LA LEY 15/2009 DE MEDIACIÓN EN EL ÁMBITO DEL DERECHO PRIVADO: UNA REFORMA PRUDENTE CON ONDA EXPANSIVA*
}

\author{
Ma Elena Lauroba Lacasa \\ Professora Titular de Dret Civil \\ Facultat de Dret Barcelona
}

\begin{abstract}
Resumen: La Ley 9/2020 de 31 de julio, que modifica el Libro II del Código Civil de Cataluña y la Ley 15/2009 de mediación en el ámbito del derecho privado, es aparentemente una reforma mínima, pero puede dar un verdadero impulso a la mediación y a las ADR en Cataluña. En primer lugar, introduce la obligatoriedad del informe previo a la mediación en dos casos: bien por acuerdo previo de las partes, bien por mandato judicial -como en la Ley 7/2015 del País Vasco-. La novedad es que el informe obligatorio trasciende el componente meramente informativo sobre las ventajas y el formato de la mediación e incluye un elemento exploratorio, centrado en evaluar su conveniencia e idoneidad para la controversia en cuestión (antes del proceso como tal). En segundo lugar, la reforma atribuye un mayor papel a los abogados para que participen en el proceso de mediación; prescribe -en su artículo sobre la imparcialidad y neutralidad de los mediadores- que éstos deben integrar la perspectiva de género en sus actuaciones (aspecto que también debe integrarse en la formación en materia de mediación) y transforma el Centro de Mediación de Derecho Privado, que ha pasado a denominarse Centro de Mediación de Cataluña, con el fin de ampliar su ámbito de actuación más allá de las controversias de derecho privado e incluso a otras ADR. En consecuencia, se anuncia un futuro estatuto para la prevención, gestión y resolución de conflictos.
\end{abstract}

Palabras clave: Mediación; ADR; Pre-mediación; Carácter obligatorio; Asistencia; papel del abogado; Confidencialidad; Perspectiva de género.

Abstract: Law 9/2020 of July 31st, modifying Book II of the Civil Code of Catalonia and Law 15/2009 on Mediation in the field of private law, is apparently a minimal reform, but it can provide a real boost for mediation and ADR in Catalonia. First, it introduces the mandatory nature of the pre-mediation briefing in two cases: either as previously agreed by the parties or pursuant to court-order-similarly as according

\footnotetext{
* e.lauroba@ub.edu. La contribución se integra en el Proyecto DER 2017-82129-P y la 2017 SGR 221. Quiero agradecer a la abogada de familia Mon Tur, presidenta de la ACDC, sus enriquecedoras observaciones.
} 
to the Basque Law 7/2015-. What's new is that the mandatory briefing transcends the merely informative component on the advantages and format of mediation and it includes an exploratory element, focused on evaluating its convenience and suitability for the dispute at hand (before the process as such). Secondly, the reform attributes a greater role to lawyers in order to involve them in the mediation process; it prescribes -in its article on mediator impartiality and neutrality- that mediators must integrate the gender perspective in their actions (an aspect also to be integrated in mediation training) and transforms the Private Law Mediation Center, which has been renamed Mediation Center of Catalonia, with the aim of extending its scope beyond private law disputes and even to other ADRs. Consequently, a future statute for the prevention, management and resolution of conflicts is announced.

Key words: Mediation; ADR; Pre-mediation; Mandatory nature; Lawyer's assistance; role; Confidentiality; Gender perspective.

SUMARIO. 1. Introducción. 2. Obligatoriedad y contenido de la sesión previa: el eje de la reforma 2.1. El alcance de la obligatoriedad 2.2. La transformación de la 'sesión informativa' en 'sesión previa', 2.3. La no confidencialidad de la inasistencia a la sesión previa 3. Las precisiones en derecho de familia: la incorporación al convenio regulador 4. Protagonismo de los abogados y rol de los colegios profesionales. 4.1. El abogado como asistente del cliente en la sesión previa y en la mediación 4.2. El abogado como informador de los ADR, una tarea que también implica a los Colegios profesionales 5 . Incorporar la perspectiva de género y los colectivos vulnerables: la nueva redacción del art. 6 LMDP. 6. La transformación del Centro de mediación: más allá de una nomenclatura dinámica. 7. Una futura ley de prevención, gestión y resolución de conflictos. 8 . Una reflexión provisional sucinta.

\section{Introducción}

Como información preliminar -y para alguno de nosotros vitamínica-, la Ley 9/2020, de 31 de julio, de modificación del Libro II del Código Civil de Cataluña [CCCat] y de la Ley 15/2009 de Mediación en el ámbito del Derecho Privado ${ }^{1}$ [LMDP] se aprobó con el voto unánime de todos los partidos. Se había tramitado por el procedimiento de lectura única. Entra en vigor a los tres meses de publicación en el DOGC, el 4 de noviembre del 2020. Ya ha dado lugar a un estupendo comentario de urgencia -en puridad, "de urgencia" solo nominalmente- del magistrado Pascual Ortuño². Aquí, también con una cierta premura, intentaremos completar su análisis.

Aunque la pandemia ha puesto los ADR como una de las estrategias destacadas para evitar el colapso de los tribunales ${ }^{3}$, la Ley 9/2020 es una iniciativa anterior

\footnotetext{
${ }^{1}$ DOGC, núm. 8193, 4 de agosto del 2020 [BOE» núm. 220, de 15 de agosto de 2020].

2 P.ORTuÑo, "Comentario de urgencia a la Ley 9/2020, de 31 de julio, de modificación del Libro II del Código civil de Cataluña y de la Ley 15/2009 de Mediación en el ámbito del derecho privado", Laley, Mediación y Arbitraje no 3, julio-septiembre 2020, pp.1-6. La publicación de este trabajo, tan lúcido como clarificador, obliga a un esfuerzo añadido para intentar decir algo más.

${ }^{3}$ Basta recordar la Consulta pública del Ministerio de Justicia sobre el anteproyecto de ley de medidas procesales, tecnológicas y de implantación de medios de solución de diferencias
} 
en el tiempo, impulsada por la Dirección de Derecho y Entidades Jurídicas del Departamento de Justicia de la Generalitat de Catalunya con la ayuda de un grupo de trabajo de la Comisión de Codificación de derecho civil de la Generalitat y la implicación de numerosos expertos en ADR y gestión de conflictos. Por eso, la iniciativa no va ligada a la pandemia. De hecho, el proyecto de ley se publicó dos días antes de la declaración del estado de alarma y en el Preámbulo ni se mencionan los desafíos post-covid. Como se afirma en el §7 Pr.:

"La presente ley tiene como objetivo fomentar la mediación y evitar que la falta de información y el desconocimiento de este medio de resolución alternativo de conflictos incline preferentemente a las partes y a los profesionales a recurrir a la vía litigiosa. (... ) Más concretamente, se pretende potenciar la mediación en el ámbito de los conflictos familiares, especialmente en aquellos que afectan a los menores de edad, atendiendo a su interés superior..."

Es una ley breve que se corresponde literalmente con su título: reforma cuatro preceptos del Libro II de Persona y Familia del Código civil de Cataluña [CCCat] (arts. 1, 2, 3 y 4, correlativo con los arts. 222-10, 233-2, 233-6 y 236-13) y cuatro preceptos de la Ley $16 / 2009$, de mediación en el ámbito del derecho privado [LMDP] (arts. 5, 6, 7 y 8, que se corresponden con los arts. 6.1; 11, 20 y 22) y añade una Disposición Adicional a dicha ley. Supone un paso más en la apuesta del legislador catalán por la mediación -familiar, pero no únicamente-, que ha ido plasmándose normativamente desde el art. 79.2 Código de Familia (ley 9/1998, de 15 de julio) hasta la reforma del 2010 del CCCat (Ley 25/2010, en cuyo §III c)114 Pr. se destaca: "El mensaje del libro II es de favorecer (...) la práctica de la mediación").

\section{Obligatoriedad y contenido de la sesión previa: el eje de la reforma}

La mejor manera de situar la reforma pasa por cotejar las redacciones inicial y actual del art. 233-6.3 CCCat, aunque nos centremos en los apartados que nos interesan.

\begin{tabular}{|c|c|}
\hline Art. 233-6 CCCat 2010 & Art. 233-6 CCCat 2020 \\
\hline $\begin{array}{r}\text { 1. Los cónyuges, en cualquier fase del } \\
\text { procedimiento matrimonial y en } \\
\text { cualquier instancia, pueden } \\
\text { someter las discrepancias a a }\end{array}$ & $\begin{array}{l}\text { 1. La sumisión a la mediación es } \\
\text { obligatoria antes de la presentación } \\
\text { de acciones judiciales si se ha } \\
\text { pactado expresamente. }\end{array}$ \\
$\begin{aligned} \text { mediación e intentar llegar a un } \\
\text { acuerdo total o parcial, excepto en } \\
\text { los casos de violencia familiar o } \\
\text { machista. }\end{aligned}$ & $\begin{array}{l}\text { demanda, en cualquier fase del } \\
\text { proceso judicial y en cualquier } \\
\text { instancia, pueden someter las }\end{array}$ \\
$\begin{aligned} \text { 2. El inicio de un proceso de mediación } \\
\text { familiar, antes de la interposición } \\
\text { de la demanda o en cualquier fase }\end{aligned}$ & a alcanzar un acuerdo, excepto en \\
\hline
\end{tabular}

https://ficheros.mjusticia.gob.es/Consulta publica APL MEDIDAS PROCESALES solucion diferencias.pd f -que permitió aportaciones hasta el 23 junio 2020-. 


\begin{tabular}{|c|c|}
\hline $\begin{array}{l}\text { del procedimiento matrimonial, a } \\
\text { iniciativa de las partes o por } \\
\text { derivación de los abogados o de } \\
\text { otros profesionales, está sujeto a } \\
\text { los principios de voluntariedad y } \\
\text { confidencialidad. En caso de } \\
\text { desistimiento, este no puede } \\
\text { perjudicar a los litigantes que han } \\
\text { participado en dicho proceso. } \\
\text { 3. La autoridad judicial puede remitir } \\
\text { a los cónyuges a una sesión } \\
\text { informativa sobre mediación, si } \\
\text { considera que, dadas las } \\
\text { circunstancias del caso, aún es } \\
\text { posible llegar a un acuerdo. } \\
\text { 4as partes pueden solicitar de } \\
\text { mutuo acuerdo la suspensión del } \\
\text { proceso mientras dura la } \\
\text { mediación. La comunicación a la } \\
\text { autoridad judicial del desistimiento } \\
\text { de cualquiera de las partes o del } \\
\text { acuerdo obtenido en la mediación } \\
\text { da lugar al levantamiento de la } \\
\text { suspensión. } \\
\text { Los acuerdos obtenidos en la } \\
\text { mediación, una vez incorporados } \\
\text { en forma al proceso, deben } \\
\text { someterse a la aprobación judicial } \\
\text { en los mismos términos que el } \\
\text { artículo } 233-3 \text { establece para el } \\
\text { convenio regulador. judicial debe } \\
\text { Los acuerdos conseguidos en } \\
\text { mediación respecto al régimen de } \\
\text { ejercicio de la responsabilidad } \\
\text { parental se consideran adecuados } \\
\text { para los intereses del menor. La } \\
\text { falta de aprobación por la } \\
\text { fundamentarse en criterios de } \\
\text { orden púbo e interés del menor. }\end{array}$ & $\begin{array}{l}\text { Ios casos de violencia familiar o } \\
\text { machista. } \\
\text { 3. Una vez iniciado el proceso judicial, } \\
\text { la autoridad judicial, a iniciativa } \\
\text { propia o a petición de una de las } \\
\text { partes o de los abogados o de otros } \\
\text { profesionales, puede derivar a las } \\
\text { partes a una sesión previa sobre } \\
\text { mediación, de carácter obligatorio, } \\
\text { para que conozcan el valor, las } \\
\text { ventajas, los principios y las } \\
\text { características de la mediación, con } \\
\text { el fin de que puedan alcanzar un } \\
\text { acuerdo. Si así lo acuerdan las } \\
\text { partes, a las que debe escucharse, } \\
\text { esta sesión puede continuar, en el } \\
\text { mismo momento o en uno posterior, } \\
\text { con una exploración del conflicto } \\
\text { que les afecta. Las partes pueden } \\
\text { decidir si optan o no por el } \\
\text { procedimiento de mediación, y } \\
\text { pueden participar en la sesión } \\
\text { previa y en la mediación asistidas } \\
\text { por sus abogados. Esta asistencia es } \\
\text { necesaria si lo requieren las partes } \\
\text { o si así lo dispone la autoridad } \\
\text { judicial y debe desarrollarse } \\
\text { siempre con pleno respeto por los } \\
\text { mediación familiar está sometido a } \\
\text { los principios de voluntariedad y } \\
\text { confidencialidad. En caso de } \\
\text { desistimiento del procedimiento de }\end{array}$ \\
\hline
\end{tabular}




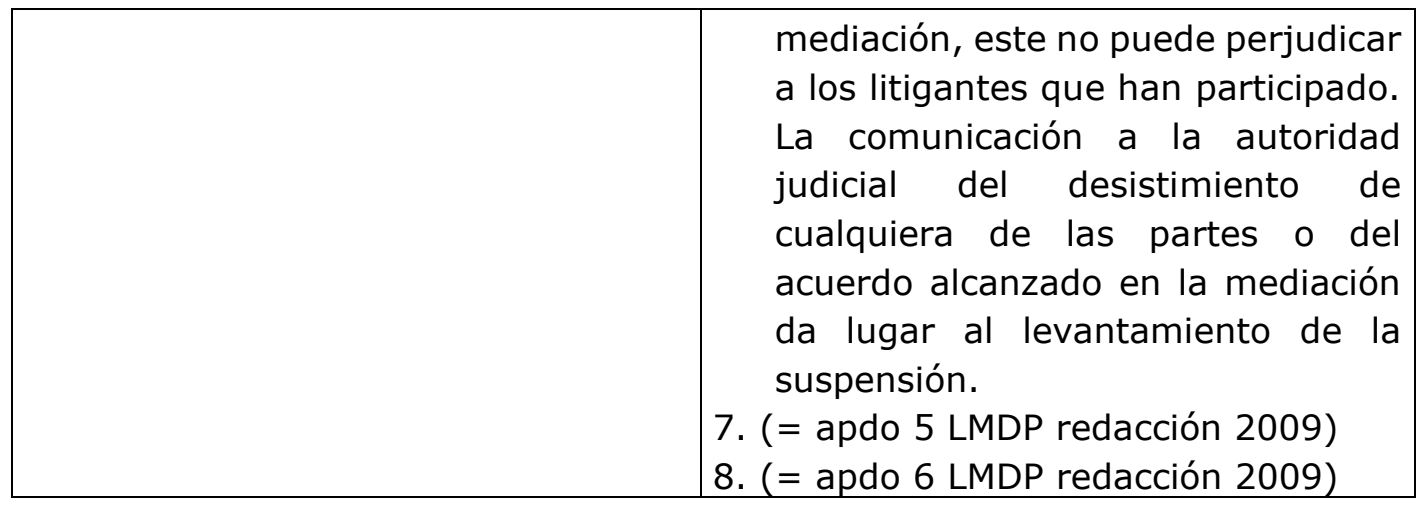

En el § 6 Pr. ley 9/2020 se hace notar que la reforma no es una novedad absoluta, pues el País Vasco ya la había adoptado: efectivamente, el art. 6 Ley $7 / 2015$, de 30 de junio, de relaciones familiares en supuestos de separación o ruptura de los progenitores ${ }^{4}$ menciona la obligatoriedad de los pactos y esa sesión obligatoria aunque más acotada/sucinta-.

\subsection{El alcance de la obligatoriedad}

La ley, pese a informaciones diversas, es modesta. Establece el carácter obligatorio de la mediación en los supuestos fijados. No procede abordar aquí la obligatoriedad de la mediación y su alcance, tema debatido ad nauseam en los últimos años ${ }^{5}$, sino insistir en la prudencia con que la recoge la Ley 9/2020. Nos centramos en el art. 233-6 CCCat, con la correlación con el art. 11 LMDP que abre los supuestos mediables más allá de lo familiar (insistiendo en conflictos relacionales).

En primer lugar -como la ley vasca- se explicita que los pactos previamente establecidos por las partes de acudir a la mediación son vinculantes. Un pacto de esas características implica intentar el procedimiento, en ningún caso continuarlo. No tendría sentido pactar acudir a mediación en los planes de parentalidad (art. 233-9.3 CCCat) y que luego quede en papel mojado, como parece que se ha pretendido ${ }^{6}$. De hecho, tras la reforma del art. 65.2 LEC por la Ley 5/2012, de 6 de julio, de Mediación en asuntos civiles y

${ }^{4} \mathrm{BOPV}$, núm. 129, de 10 de julio de 2015 (BOE, núm. 176, de 24 de julio de 2015). Artículo 6. De la mediación familiar. 1. Los progenitores podrán en todo momento someter voluntariamente sus discrepancias a mediación familiar con vistas a lograr un acuerdo sobre el régimen de custodia, entre otros aspectos. El sometimiento a la mediación familiar será obligatorio con anterioridad a la presentación de acciones judiciales cuando así se hubiera pactado expresamente antes de la ruptura. // 2. Una vez iniciado el proceso, el juez, a iniciativa propia o a petición de una de las partes, y a los efectos de facilitar un acuerdo entre estas, podrá derivarlas con carácter obligatorio a una sesión informativa de mediación intrajudicial a fin de que sean informadas sobre dichas medidas, su funcionamiento y beneficios. En dicha sesión las partes podrán comunicar al mediador o mediadora su decisión de continuar o no el proceso de mediación

${ }^{5}$ Muy útil E.Ginebra - J.TARABAL, "Mediación obligatoria e inducción a la mediación", en E.LAurobaP.ORTuÑo, Mediación es justicia. El impacto de la Ley 5/2012 de mediación civil y mercantil, Huygens Editorial, 2014, pp. 227-234.

6 Como recuerda ORTUÑO, "Comentario de urgencia...", op.cit., p. 4/6, se desvanecen las dudas interpretativas al respecto, tanto cuando se han incluido en los Planes de Parentalidad, como si aparecen en las propuestas contradictorias en las demandas contenciosas. 
mercantiles [LMACM], esta reflexión debería haberse zanjado7. Y hablamos de sesión previa, ajena a la contundencia de la propuesta del Anteproyecto de Ley de Mediación de Asuntos civiles y Mercantiles (19.2.2010) ${ }^{8}$ que no recuperó la LMACM.

En segundo lugar, la autoridad judicial puede enviar a esa sesión obligatoria si estima que es posible que alcancen un acuerdo. Puede decidirlo a iniciativa propia -así sucedía, sucintamente, antes- o si lo solicita una de las partes (no necesariamente las dos) o sus abogados u otros profesionales (esa legitimación de los otros profesionales sorprende, porque no la intuimos muy exitosa...). El envío puede ser en cualquier fase del proceso y en cualquier instancia, como ya se prescribía en el 2010, para reflejar que también en apelación. Lo detalla el art. 12.1.b) LMDP: la mediación puede iniciarse "cuando el proceso judicial está pendiente, en cualquiera de las instancias y los recursos, en ejecución de sentencia o en la modificación de las medidas establecidas por una resolución judicial firme, en los términos que determine la legislación procesal". Ahora bien, cabría preguntarse si en un procedimiento de ejecución correlativo a una sentencia declarativa, ante la falta de cumplimiento voluntario de lo que esta establece, tiene utilidad pretender la mediación, salvo si las partes lo acuerdan de común acuerdo, que es otra historia 9 .

\subsection{La transformación de la sesión informativa en sesión previa}

La sesión informativa adquiere, con la Ley 9/2020, un contenido más ambicioso, porque incorpora una segunda fase exploratoria (vid. art. 233-63). Pasa a denominarse sesión previa para recalcar, a nuestro juicio, su condición de fase anterior a la mediación stricto sensu. Lo prueba indubitadamente el art. 11 LMDP [antes Rúbrica "Sesión informativa", ahora Rúbrica "Sesión previa"] diferente del art. 15 ["Reunión inicial"] y antes del art. 12 ["Inicio de la mediación"].

Apunta Ortuño -buen conocedor de la casuística-, que en la práctica se han detectado casos en que la negativa a acudir a mediación se realiza "de forma

\footnotetext{
7 Sobre el tema, E.GineBRA - J.TARABAL, "La obligatoriedad de la mediación derivada de la voluntad de las partes: las cláusulas de mediación", InDret, 2013-4.

8 https://estaticos.expansion.com/estaticas/documentos/2010/04/mediacion.pdf (última consulta 7.10.2020). Ex art. 7 [Voluntariedad]: "El sometimiento a mediación es voluntario, sin perjuicio de la obligatoriedad de su inicio cuando lo prevea esta ley o la legislación procesal. Nadie está obligado a concluir un acuerdo ni a mantenerse en el procedimiento de mediación".

${ }^{9}$ Lo anticipaban los comentarios al art. 233-6 CCCat. Así, P. ORTUÑo, "Comentario al art. 233-6" en EGEA I FERnÁndez-J.FerRer i Riba (dirs.), E.FARnos i Amorós (coord..), Comentari al Llibre segon del Codi civil de Catalunya, Ed. Atelier, Barcelona, 2014, ps. 417-418, abría la remisión tanto a la fase de medidas provisionales, como en las de alegaciones, audiencias previas e incluso durante la tramitación de la apelación; consideraba especialmente indicada la fase de ejecución cuando el problema era el ejercicio de la responsabilidad parental, guarda y relaciones personales. Para I.ToMÁs, "Comentario al art. 233-6", en P.ORTuÑo (coord.), Persona y Familia. Libro Segundo del Código civil de Cataluña, Sepín, Madrid, 2011, p. 844: "se permite tanto en la fase declarativa como en la fase de ejecución, en medidas provisionales como en el pleito principal y tanto en la primera como en la segunda instancia, y hay que entender también en la fase de los recursos extraordinarios".
} 
automática y sin un real consentimiento informado de las partes", de ahí que la ley persiga introducir el mensaje "de que no basta con una negativa burocrática, sino que ha de exigirse un mínimo conocimiento de causa por las propias partes interesadas -y no solo de sus abogados- de lo que es la mediación y de lo que podría aportar positivamente al caso concreto, así como de las consecuencias negativas de la vía contenciosa"10. Ese parece el propósito del legislador, cuando apunta que "esta sesión puede continuar...", aunque existe un margen de ambigüedad. Basta leer la explicación del § 8 Pr.:

"En esta sesión previa se informa a las partes del funcionamiento, las características y los beneficios de la mediación, para que, libremente y de forma fundamentada, puedan analizar y decidir si desean iniciar el proceso de mediación. Asimismo, se prevé la posibilidad de que la sesión previa pueda continuar con una exploración del conflicto, si así lo acuerdan las partes, a las que hay que escuchar, opción que puede favorecer el ahorro de tiempo y trámites y acercar aún más a las personas afectadas a la mediación."

Se continúa, ergo seguimos antes de..., con esa voluntad "de acercar más a las personas afectadas a la mediación". La exploración del conflicto no da lugar a una unidad autónoma, sino que es un aspecto de la sesión previa ('previa' a la mediación como tal). Podría contribuir a la confusión que el art. 11.4 LMDP afirme que "el órgano público correspondiente facilita la sesión previa y vela, si procede, por el desarrollo adecuado de la mediación", pero la frase ya aparecía en la redacción inicial, ergo no contesta esta tesis ${ }^{11}$.

Dicho esto, dado que la exploración puede "continuar en el mismo momento o en uno posterior" hemos de admitir opiniones discrepantes. En la práctica, la sesión informativa no siempre se ha hecho conjuntamente: el responsable puede informar primero a una parte y después a otra, si el nivel de hostilidad/acritud lo hace aconsejable ${ }^{12}$; también, según explican los propios mediadores, a menudo las sesiones individuales obedecen a que una parte, dubitativa, pide una información ajustada antes de sugerírselo a la otra parte ¿podrá tener lugar entonces la segunda parte, la continuatio...? Parece que sí. El hecho de ser escuchadas, según recalca el artículo -la enésima modalidad de consentimiento informado, pues consienten cuando ya conocen qué es la mediación-, legitima cualquier intervención ulterior.

Las dudas que pueden suscitarse sobre su encaje con la primera sesión de mediación obedecen, creemos, a la intuida superposición de contenidos/actuaciones, y es un debate que viene de lejos, porque en la

\footnotetext{
10 ORTUÑo, "Comentario de urgencia...", op.cit., p. 5.

${ }^{11}$ La confusión podría aparecer en la frase siguiente del art. 11: "Las partes pueden decidir si optan o no por el procedimiento de mediación, y pueden participar en la sesión previa y en la de mediación asistidas por sus abogados, donde la mención a "la de mediación" podría llevar a pensar que la exploración ya es procedimiento de mediación. Debiera constar en plural.

12 A.Guillamat-M.Canyameres, "Comentario al artículo 11", en I.Viola (dir.) / I.Barral-E. Lauroba (coords.), Comentarios a la Ley catalana 15/2009, de 22 de julio, de mediación en el ámbito del Derecho Privado y concordantes, Marcial Pons, Madrid-Barcelona-Buenos Aires-Sao Paolo, 2018, p. 87.
} 
redacción del 2009, el contenido de la sesión inicial (art.15.1 y 3 LMDP) coincidía con el de la informativa -solo que en la praxis solían hacerlo profesionales diferentes-; por ello los algunos expertos estimaban, tras años de aplicación, que había que reajustar el modelo de sesión informativa y destacaban "el valor medial que conlleva ya la interacción entre el mediador informador y las partes"13. El legislador parece haberlos escuchado.

La regulación novedosa suscita, empero, interrogantes. Si las partes acuerdan la segunda fase, esa primera aproximación al que es su conflicto también debería estar sujeta a la confidencialidad, porque la exención (vid. infra) va ligada a la inasistencia, no a los contenidos.... Y eso pese a que todavía no han iniciado la mediación como tal ${ }^{14}$. Por otro lado, en Cataluña, las sesiones informativas son facilitadas en un porcentaje relevante por el personal del Centro de mediación de la Generalitat, que no actuará como mediador en el proceso subsiguiente, pues se debe designar a un mediador del registro de mediadores de dicho centro ${ }^{15}$, sin olvidar que también los colegios profesionales facilitan sesiones informativas.... Habrá que esperar a la implementación efectiva de la ley 9/2020.

\subsection{La no confidencialidad de la inasistencia a la sesión previa}

Los arts. 233-6.4 CCCat y 11.1 in fine LMDP prescriben que la confidencialidad -principio básico de la mediación-, no se extiende a la inasistencia no justificada a la sesión informativa. Como recuerda el $\S 8$ in fine $\operatorname{Pr}$. ley $9 / 2020$, "se trata de un principio que ya han adoptado otros textos legales sobre esta materia, tales como el artículo 17 de la ley del Estado 5/2012, de 6 de julio, de mediación en asuntos civiles y mercantiles". Hay un matiz, empero, menor: ex art. 17.1 in fine LMACM [Información y sesiones informativas], tenemos un mediador/ institución de mediación que cita a las partes para la sesión informativa y si no asisten de manera injustificada "se entenderá que desisten de la mediación solicitada. La información de qué parte o partes no asistieron a la sesión no será confidencial" 16 . En la ley 9/2020 la redacción es más contundente: la inasistencia "debe ser comunicada a la autoridad judicial", como efecto colateral (también recalcado en el art. 11 LMDP).

\footnotetext{
${ }^{13}$ Guillamat-CANYAMERES, "Comentario al artículo 11", op.cit., p. 87. Vid. también en relación con la LMACM, C.Torrado TARrío, "Comentario al art. 17" en R.CASTIllejo (dir.), Comentarios a la Ley 5/2012, de Mediación en asuntos civiles y mercantiles, Tirant lo Blanch, Valencia, 2013, pp.197-198, crítica con las opciones autonómicas que, a su juicio, mezclan conceptos.

${ }^{14}$ Para subrayar la complejidad de la situación o las dudas que genera, ORTUÑo, al comentar el art. 233-6 inicial (op.cit., p. 417) afirmaba que: "En realitat és una primera sessió de mediació".

15 De hecho, Guillamat-Canyameres, op.cit., p. 88, atendiendo a la interacción entre el mediador informador y las partes, estimaban que "sería deseable que tuviera continuidad, y que el propio mediador informador fuera el que llevase a cabo la mediación" y concluían "así sucede habitualmente en el ámbito privado, pero no en el sector público".

${ }^{16}$ La redacción avala, a juicio de algunos estudiosos, cómo estamos todavía en un momento previo al proceso de mediación stricto sensu (TORRADO TARRío, "Comentario al art. 17", op.cit., pp.197-198).
} 
A día de hoy, la negativa a acudir a mediación no tiene consecuencias procesales/sancionatorias a posteriori, como en otros países ${ }^{17}$. Sencillamente, conlleva que su señoría conozca la falta de voluntad injustificada- de la parte de implicarse en un procedimiento que puede ayudarla a solventar por sí misma su conflicto. En buena medida -solo nos atrevemos a apuntarlo- tiene que ver con los nuevos valores sociales. Hoy no solo un fenómeno pandemial o postpandemial- la voluntad/carga de cooperar se estima una actitud a preservar ( $y$ se está extendiendo a diferentes ámbitos de la sociedad, baste citar el collaborative Health, como salvaguarda de los derechos de los pacientes, por no hablar del ecosistema de la economía colaborativa, que tanto trabajo nos va a dar como civilistas...). Situémonos con un paralelismo en otro ámbito del derecho civil: en un mundo en el que el derecho de contratos ya explicita el principio de cooperación para el mejor desarrollo de las transacciones ${ }^{18}$, la autoexclusión desde el principio de un ADR basado en la responsabilidad del 'titular' del conflicto no parece que deba quedar "impune". Más cuando acudir y desistir después no le resulta lesivo (ex art. 233-6.6 cCCat: "en caso de desistimiento del procedimiento de mediación, este no puede perjudicar a los litigantes que han participado"). En buena medida, acudir a esa sesión previa es una manifestación particular de la buena fe (que, ex art. 111-7 CCCat, debe observarse siempre en las relaciones jurídicas privadas). Y, si nos circunscribimos al derecho de familia, asistir es una prueba de la voluntad de actuar en interés del menor, una manifestación de deseado "ejercicio positivo de la parentalidad" [o coparentalidad positiva] plasmado tempranamente en la resolución del $2006^{19}$ y que progresivamente va consolidándose en la jurisprudencia y entre los especialistas en derecho de familia.

\section{Las precisiones en derecho de familia: la incorporación en el convenio regulador}

La ley 9/2020 reforma otros tres preceptos vinculados al derecho de familia, más allá del art. 233-6 [norma general]. Interesa especialmente el art. 233-2.7 CCCat, que especifica que "el convenio puede incluir pactos de sometimiento a mediación y otros mecanismos alternativos de resolución de conflictos". Hasta ahora, la mediación se mencionaba en el Plan de Parentalidad, una de las novedades del Libro II CCCat. (ex § III c) 12 Pr. Ley 25/2010) para proteger mejor a los

\footnotetext{
$17 \mathrm{Y}$ es una posibilidad contemplada desde el inicio. Basta recordar el Considerando 14 Directiva 2008/52/CE del Parlamento Europeo y del Consejo de 21 de mayo de 2008 sobre ciertos aspectos de la mediación en asuntos civiles y mercantiles: "Nada de lo dispuesto en la presente Directiva debe afectar a la legislación nacional que haga obligatorio el uso de la mediación o que la someta a incentivos o sanciones, siempre que tal legislación no impida a las partes el ejercicio de su derecho de acceso al sistema judicial (el subrayado es nuestro). Algún magistrado en nuestro país defiende, no obstante, recurrir a la figura de la mala fe procesal...

${ }^{18}$ Baste pensar en los Principios UNIDROIT (Principio 5.1.3) o en el art. 511-2 ["Buena fe y deber de cooperación"] de la Propuesta de Código civil de la Asociación de profesores de derecho civil (Ed. Tecnos, 2018)

${ }^{19}$ Recomendación Rec (2006)19 del Comité de Ministros a los Estados Miembros sobre políticas de apoyo al ejercicio positivo de la parentalidad.
} 
menores, al deslindar adecuadamente las cuestiones que los afectan (art. 233$9.3 \mathrm{CCCat}^{20}$ ). Ahora la ley dota de mayor visibilidad una cláusula que ya se podía pactar, lo que, atendiendo a la función pedagógica de las normas, facilitará su inserción en la práctica. Es de desear que se incluya en los Modelos de convenios que usan los abogados.

Asimismo, se modifican los arts. 222-10 y 236-13 CCCat. Mencionaban el recurso a mediación cuando varias personas se disputan devenir tutores o en los desacuerdos en el ejercicio de la potestad parental ${ }^{21}$. La Ley 9/2020 no introduce nuevas cuñas pro mediación en otras situaciones: la enumeración de conflictos familiares ya tiene su sede -vocacionalmente exhaustiva- en el art. 2.1 LMDP. Aquí solo se pretende incorporar la nueva redacción del art. 233-6 CCCat: 'sesión previa' obligatoria y acompañamiento de los abogados (vid. infra).

\section{Protagonismo de los abogados y rol de los colegios profesionales}

La norma persigue incrementar la implicación de los abogados en la mediación, como actores en el procedimiento e impulsores de la figura. Hasta ahora, el art. 11 LDMP [sesión informativa] señalaba que el mediador explicaba a las partes la conveniencia del asesoramiento legal y de la intervención de los letrados en la redacción ulterior del convenio o documento en que se "juridificaban" los acuerdos alcanzados en mediación ${ }^{22}$. En la práctica los abogados asistían muy pocas veces a las sesiones de mediación familiar y su sentimiento de exclusión se agudizaba cuando recibían unos acuerdos no fáciles de traducir a un convenio y que -a su juicio- no salvaguardaban satisfactoriamente los intereses de sus clientes. Hemos apuntado reiteradamente que en la abogacía coexisten los sectores pro y contra ADR. En otro texto de este blog CESCO afirmábamos que "Hoy todavía muchos abogados sienten la mediación como una figura que los amenaza o que los excluye. ${ }^{23}$. Implicarlos adecuadamente es imprescindible para consolidar los ADR.

\footnotetext{
20 "3. Las propuestas de plan de parentalidad pueden prever la posibilidad de recurrir a la mediación familiar para resolver las diferencias derivadas de la aplicación del plan, o la conveniencia de modificar su contenido para amoldarlo a las necesidades de las diferentes etapas de la vida de los hijos". Vid. E. LAUROBA, "Los Planes de Parentalidad en el Libro Segundo del Código civil de Cataluña", RJC, 2012, pp. 887-916.

${ }^{21}$ Vid. E.LAuroba, "La mediación en Cataluña", en N.GinÉs (coord.), Familia del siglo XXI: algunas novedades del libro II del Código civil de Cataluña, J.M. Bosch, ed., Barcelona, 2011, pp. 141-193.

${ }^{22}$ Art. 15.3 LMDP [Reunión inicial]: "La persona mediadora ha de informar a las partes de la conveniencia de recibir asesoramiento jurídico durante la mediación y de la necesidad de la intervención de un abogado o abogada designado libremente para redactar el convenio o el documento jurídico adecuado, sobre la base del resultado de la mediación. (...)"; Vid.A.VALL Rius, "Comentario al artículo 15", en I.Viola (dir.) / I.BARRAL-E. LAURoBA (coords.), Comentarios a la Ley catalana 15/2009, de 22 de julio, de mediación en el ámbito del Derecho Privado y concordantes, Marcial Pons, Madrid-Barcelona-Buenos Aires-Sao Paolo, 2018, pp. 109-113.

23 E. 23 "Yo medio, tú medias, él media..." http://centrodeestudiosdeconsumo.com/images/20. ELENA LAUROBA LACASA -

Yo medio tu medias el media.pdf. Añadíamos "Como prueba mensurable, un estudio sobre el uso posible de la mediación en conflictos de seguros concluía que un $90 \%$ de los abogados del sector la miraban con desconfianza". Efectivamente, un estudio sobre cómo implementar la mediación en los seguros (patrocinado por la compañía aseguradora DAS) a partir de la metodología del focus group con operadores jurídicos de ese ámbito, concluyó que los abogados pro mediación en el sector apenas alcanzaban el 10\%
} 
Desde esa premisa, la ley 9/2020 desdobla su intervención en dos acciones: acompañar a las partes durante la sesión previa y/o la mediación y haberlas informado -informarlas- sobre la existencia y utilidad de los ADR.

\subsection{El abogado como asistente del cliente en la sesión previa y en la mediación}

El nuevo formato de la sesión previa (información/exploración) puede hacer más conveniente la presencia de los abogados. Durante años se ha discutido la utilidad de que acompañasen a sus clientes a sesiones meramente informativas previas al procedimiento como tal, pues eran meros convidados de piedra; ahora, al existir ese posible desdoblamiento en una segunda fase resultan -se estima- más valiosos. La ley 9/2020 especifica que pueden acompañar a las partes si estas así lo desean e incluso si lo prescribe la autoridad judicial -lo que resulta algo extraño, aunque quizás sea un espaldarazo definitivo a la figura... -. Se señala que asistirán con pleno respeto por los principios de la mediación y por la igualdad de las partes. Esta precisión aparece en los arts. 233-6 CCCat y 11 LMDP y también en los supuestos específicos de los arts. 222-10.4 y 236-13 CCCat. Es fruto de una enmienda ${ }^{24}$ y no sabemos si suficientemente sopesada (aunque estéticamente reconfortante). Quizás pueda ser a la postre benéfica: implica deber de confidencialidad desde el principio -en cuanto contenidos- y parece convertirlos en garantes del buen funcionamiento de la mediación ¿coadyuvando al propio mediador? (aunque ellos no son imparciales, obviamente...).

\subsection{El abogado como informador de los ADR, una tarea que también implica a los Colegios profesionales}

La nueva D.A 4a LMDP recoge el deber de los abogados de informar a sus clientes sobre los ADR y de procurar resolver sus propios conflictos en el ejercicio de su profesión -con otros colegiados, o con sus clientes- por dichas vías. Enlaza con las obligaciones que fija el Código Deontológico de la Abogacía española (CDAE, aprobado por el Pleno del Consejo de la Abogacía española el 6 de marzo de 2019): el art. 12 CDAE [Relaciones con los clientes] apdo. 8 prescribe que los abogados deben asesorar al cliente sobre los instrumentos de resolución de $\operatorname{conflictos}^{25}$ y el art. 11 [Relaciones entre profesionales de la abogacía] apuesta por la mediación como medio privilegiado para abordar conflictos entre abogados. A nuestro juicio, si los abogados se concienciaran adecuadamente de esta tarea, ellos podrían ser los mejores transmisores de las ventajas, valores, principios y

(vid. E.LAUROBA, "La mediación en el sector asegurador: mediar tras un siniestro y mucho más...", en M.GARCía MAYo, La mediación en las diversas disciplinas jurídicas, Ediciones Olejnik, 2020, p. 202)

24 BOPC n.657, viernes 24 julio 2020. Enmienda n.2 del GP socialista-Units per avançar (vid.ps, 3-4)

25 "Se asesorará y defenderá al cliente con el máximo celo y diligencia asumiéndose personalmente la responsabilidad del trabajo encargado sin perjuicio de las colaboraciones que se recaben. Siempre se deberá intentar encontrar la solución más adecuada al encargo recibido, debiéndose asesorar al cliente en el momento oportuno respecto a la posibilidad y consecuencias de llegar a un acuerdo o de acudir a instrumentos de resolución alternativa de conflictos" 
características de la mediación, esto es, de lo que ha constituido el contenido tradicional de la sesión informativa. Un desiderátum a día de hoy, pero que valdría la pena retener -y recordar a los abogados reticentes que, puesto que formaría parte de su cometido profesional, no pro bono...-

Paralelamente, los colegios profesionales deben velar por el cumplimiento de ese deber de información. Desde la ley del 2001, los colegios profesionales han tenido un marcado protagonismo en la gestión/fomento de la mediación, ordenado en las funciones que enumera el art. 22 LMDP. Sucintamente, antes de la reforma, el apartado d) mencionaba "Cumplir la función deontológica y disciplinaria respecto de los colegiados que ejercen la mediación". Ahora incluye "y velar por que el conjunto de colegiados cumpla las funciones de información a los clientes y de fomento y sujeción a la mediación que le imponen las leyes o los códigos deontológicos respectivos". Consta que las comisiones de deontología impulsan las mediaciones, pero previsiblemente habrá que idear otros mecanismos para poder velar de manera efectiva, entendiéndolo no como mera fiscalización, sino como cooperación para el mejor desempeño de dicha tarea.

\section{Incorporar la perspectiva de género y las personas vulnerables: la nueva redacción del art. 6 LMDP}

El art. 6 [Imparcialidad y neutralidad] modifica su redacción de la siguiente manera:

\begin{tabular}{|l|l|l|}
\hline Art. 6 LMDP [2009] & \multicolumn{2}{|c|}{ Art. 6 LMDP [2020] } \\
\hline "La persona mediadora ejerce su función & "La persona mediadora ejerce su \\
con imparcialidad y neutralidad, & función con imparcialidad y neutralidad, \\
garantizando la igualdad entre las partes. & con perspectiva de género, \\
$\mathrm{Si}$ es preciso, debe interrumpir la la & garantizando la igualdad entre las \\
mediación mientras la igualdad de poder & partes y la protección de las personas y \\
y la libertad de decidir de las partes no no & los colectivos vulnerables. [Si es \\
esté garantizada, especialmente como & preciso... se mantiene la redacción \\
consecuencia de situaciones de violencia. & anterior]. \\
En todo caso, debe interrumpirse &
\end{tabular}

El art. 6 plasma dos principios nucleares de la mediación, la imparcialidad y la neutralidad, con el plus del respeto a la igualdad de partes. Ahora, a partir de una enmienda ${ }^{26}$ se añade una referencia a la perspectiva de género y se garantiza la protección de los colectivos vulnerables. Veamos qué consecuencias puede comportar en la práctica.

En primer lugar, procede deslindar perspectiva de género de violencia machista. La prohibición de la mediación en caso de violencia familiar o machista es una constante. En la LMPD consta en el art. 6 desde la redacción original y también en la redacción original del art. 233-6 CCCat (entonces apdo 1) y ahora en el art. 233-6.2 in fine CCCat, siempre de forma taxativa. Justamente Ortuño deplora que

${ }^{26}$ DOGC, núm. 657, 24 julio 2020, p.5, Enmienda n. 1 Grupo En común podem. 
se mantenga esta rigidez pues su fundamento último es el convenio de Estambul [el Convenio del Consejo de Europa sobre prevención y lucha contra la violencia contra las mujeres y la violencia doméstica, 2011] que proscribe la obligatoriedad, pero no la posibilidad de utilizarla cuando la propia mujer la solicita en uso de su legítimo derecho ${ }^{27}$. En su momento afirmamos que excluir los casos de violencia de la mediación desde una abstracción sin excepciones, puede acabar perjudicando a las mujeres (presupone que no habrá manera de empoderarlas en el conflicto ${ }^{28}$, pero no parece que ese criterio vaya a cambiar en los próximos años.

El interés de abordar el conflicto desde una perspectiva de género implica que el mediador sea consciente de la singularidad de cada una de las partes. Somos conscientes de que para algunos estudiosos la mediación, como instrumento autocompositivo, beneficia a quienes están ya empoderados para la negociación en general y puede perjudicar a las mujeres y a otros colectivos menos poderosos/más débiles ${ }^{29}$. Pero la propia ley, además de mencionar la igualdad, establece "un segundo deber más concreto que se relaciona con la detección y corrección de asimetrías entre las partes" ${ }^{30}$. En ese caso, el mediador debe interrumpir el procedimiento si no puede garantizar la libertad de decidir y es un caso no ligado necesariamente a la violencia. Este deber se desarrolla en el art 25 Reglamento LMDP [RMDP] ${ }^{31}$ : "2. La persona mediadora ha de procurar evitar desequilibrios de poder entre las partes aplicando las técnicas necesarias para reconducir estas situaciones. Ha de dar por acabada la mediación cuando no sea posible restablecer el equilibrio (...)". En suma, corresponde al mediador desarrollar una neutralidad activa, porque "no es desde el poder o la influencia

\footnotetext{
27 ORTUÑO, "Comentario de urgencia...", op.cit., p. 2/6.

28 E. LAUROBA LACASA, "Instrumentos para una gestión constructiva de los conflictos familiares: mediación, derecho colaborativo, arbitraje ¿y...?", InDret, 2018/4, pp.15-16.Y mencionábamos materiales de derecho comparado.

29 Posiblemente el texto de referencia para cuestionar la mediación para los grupos vulnerables ha sido R.Delgado, C.Dunn, P.Brown, H.LeE, D.Hubbert, Fairness and Formality: Minimizing the Risk of Prejudice in Alternative Dispute Resolution, Wis. L. REv. 1359 (1985). Vid. también, como otra referencia valiosa, Margaret F. BRINIG, "Does Mediation Systematically Disadvantage Women?", William \& Mary Journal of Women and the Law, 1995, vol.2/1, pp.1-34. Su conclusion (p.34) es una síntesis perfecta: "Many women who have tried mediation liked it. However, congested courts cannot justify mandatory mediation in cases where one spouse holds a monopoly on marital power. No one should order mediation when there has been abuse within the family, substance abuse, or systematic hiding of assets". Como contribuciones recientes, C. IzUmI, "Implicit Bias and Prejudice in Mediation", SMU Law Review, 70, n. 3, 2017, pp. 681694; N.A.WELSH, "Do You Believe in Magic: Self-Determination and Procedural Justice Meet Inequality in Court-Connected Mediation", SMU Law Review, vol. 70, n.3, 2017, pp. 721-762; Ch.B CRAVER, "Do Alternative Dispute Resolution Procedures Disadvantage Women and Minorities", SMU Law Review, vol. 70, no. 4, Fall 2017, pp. 891-912. Como última referencia valiosa, Y.GonZÁLEZ FERRER, "Mediación familiar con perspectiva de género. Una necesidad impostergable para la efectiva resolución armónica de conflictos", M. GARCíA MAYO (dr.), La mediación en las diversas disciplinas jurídicas, Ediciones Olejnik, 2020, pp. 225-255.

${ }^{30}$ I. BARRAL, "Comentario al artículo 6", en I.Viola (dir.) / I.BARRAL-E. LAUROBA (coords.), Comentarios a la Ley catalana 15/2009, de 22 de julio, de mediación en el ámbito del Derecho Privado y concordantes, Marcial Pons, Madrid-Barcelona-Buenos Aires-Sao Paolo, 2018, pp. 54-61

${ }^{31}$ Decreto 135/2012 de 23 de octubre, por el cual se aprueba el Reglamento de la Ley 15/2009, de 22 de julio, de mediación en el ámbito de derecho privado.
} 
que la persona mediadora debe corregir las asimetrías, sino desde sus propias herramientas para la intervención". ${ }^{32}$

Ahora bien, la perspectiva de género no debe vincularse exclusivamente a una concepción de hipotética asimetría -en la negociación, por ejemplo-, sino a la asunción de que objetivos y preocupaciones de la negociación tras la ruptura de la familia -la crianza de los hijos frente a cuestiones económicas-, difieren en función del género ${ }^{33}$, del mismo modo -y sin entrar en debates extemporáneosque un estudio empírico ha demostrado que las mujeres con enfermedades graves/crónicas experimentan un mayor riesgo de divorcio ${ }^{34}$. Esa es la perspectiva a explorar, creemos.

Paralelamente la DF 2a (enmienda 3 GP En Comú podem) prescribe que -en el plazo de un año- "el desarrollo reglamentario de la formación en el ámbito de la prevención, gestión y resolución de conflictos debe incorporar la perspectiva de género y la protección de las personas y los colectivos en situación de desigualdad". Supondrá modificar la Orden JUS/428/2012, de 18 de diciembre ${ }^{35}$. Hay que tener presente que los colegios profesionales a día de hoy ya tienen entre sus funciones en relación con la mediación (art. 22 j) LMDP: "Llevar a cabo formación de capacitación en materia de violencia en el ámbito familiar, para detectar e identificar situaciones de riesgo, prestando una especial atención a las que afecten a personas en situación de dependencia". Aunque, de acuerdo con lo expuesto supra, puede configurarse como una formación autónoma (o parcial para los nuevos propósitos).

La mención a la protección de la personas y colectivos vulnerables es un recordatorio, pero no modifica la actuación del mediador ni los deberes que ya recogía la LMDP. Así, el mediador "comunica a las partes la necesidad de velar por el interés superior en juego" (art. 13.c); "debe prestar una atención particular a cualquier signo de violencia, física o psíquica entre las partes" (art. 14.2); y se recuerda que "Los acuerdos han de dar prioridad al interés superior de los menores y de las personas incapacitadas" (art. 19.2) -en el art. 25.4 RLMDP se mencionan "los niños y adolescentes o de las personas discapacitadas o de aquellas más necesitadas de atención y asistencia"-. La pregunta, que solo podemos formular aquí es ¿quiénes son exactamente esos colectivos vulnerables

\footnotetext{
32 R.CAlvo, "Comentario al art. 14", en I.Viola (dir.) / I.BARRAL-E. Lauroba (coords.), Comentarios a la Ley catalana 15/2009, de 22 de julio, de mediación en el ámbito del Derecho Privado y concordantes, Marcial Pons, Madrid-Barcelona-Buenos Aires-Sao Paolo, 2018, p. 106.

${ }^{33}$ Lo desarrolla, de manera incontestable, A.BARLow, "Solidarity, Autonomy and Equality: Mixed Messages for the Family", 27 Child \& Fam. L. Q., 2015, pp.223- 236. Vid también C.Gonzalez Beilfuss, "Reflexiones en torno a la función de la autonomía de la voluntad conflictual en el derecho internacional privado de familia", Revista Española de Derecho Internacional, vol. 72, n. 1, 2020, pp. 101-116, que dedica el tercer bloque a "Autonomía y vulnerabilidad" (pp. 109-114), con una afirmación que anticipa debates de calado: "La teoría de la vulnerabilidad pone en el centro del discurso el mundo de los cuidados. Históricamente se trata de un mundo que es femenino...". Por ultimo, D. Del GobBo, "The Feminist Negotiator's Dilemma", Ohio State Journal on Dispute Resolution, vol. 33, n.1, 2018, pp. 1-64

${ }^{34}$ A. KARRAKER-K.LATHAM, "In Sickness and in Health? Physical Illness as a Risk Factor for Marital Dissolution in Later Life", Journal of Health and Social Behavior, 2015, vol. 56(3), pp.420-435.

35 Orden... por la cual se regulan los contenidos básicos y el procedimiento de homologación de la formación específica en materia de mediación en el ámbito del derecho privado (DOGC núm. 6282, de 8 de diciembre 2012).
} 
más allá de los grupos ya identificados? ¿la tercera edad? ¿los consumidores, pese a tener regulación específica?

\section{La transformación del Centro de Mediación: más allá de una nomenclatura dinámica}

El Centro de Mediación de Derecho privado de Cataluña [CMCat] experimenta cambios relevantes. Ex art. 20, la denominación actual es Centro de Mediación de Cataluña, pero su objeto se amplía, más allá del cambio de nombre. En la nueva redacción (art. 20.2 LMDP):

"El Centro de Mediación de Cataluña tiene por objeto promover administrar la mediación y otros métodos alternativos de resolución de conflictos"

Como revela el $\S 11$ Pr., "el objeto del Centro de Mediación de Derecho privado de Cataluña se extiende no solo a promover y administrar la mediación, sino también a la promoción y administración de otros métodos alternativos de resolución de conflictos", de ahí que el nombre del Centro [Disposición Adicional Primera] sea, a partir de ahora, Centro de Mediación. La razón es simple, desde la Dirección correspondiente (la Dirección de Derecho y Entidades Jurídicas) se ha lanzado en todos los foros un mensaje congruente y aplaudible para los defensores de la mediación: ¿cómo vamos a poder consolidarla si la Administración pública no la adopta? Por ello, entre otras acciones, se ha impulsado un programa piloto en la jurisdicción contencioso-administrativa. Ahora bien, el objeto es más ambicioso, porque integra "otros mecanismos alternativos". Dicho esto, más allá de la nueva denominación "oficial", la Disposición Adicional $1^{a} .3$ prescribe que "El centro, en su actividad ordinaria, también puede emplear la denominación Centro ADR Justicia u otras que se refieran de forman inequívoca a la gestión de la resolución extrajudicial de conflictos" [Disposición Adicional 1a.3]. Es una manera heterodoxa $-y$ quizás contestable, si no fuera por la urgencia y acotación de la reforma- de consolidar una tarea que a día de hoy el centro ya está impulsando ${ }^{36}$. Baste recordar diversas acciones en relación con la coordinación parental -empezando por un programa piloto ${ }^{37}$ - que han permitido dar a conocer y testar este ADR o la gestión de los Premios ADR Justicia. A día de hoy, el centro también ha contribuido a difundir la formación en derecho colaborativo que impulsa la Asociación catalana de derecho colaborativo $(A C D C)^{38}$ y es de prever que en el futuro colabore más estrechamente con ella. Hubiera sido adecuado explicitarlo en la relación de las funciones que tiene atribuidas (art. 21 LMDP), en aras de la mejor técnica legislativa, pero creemos que primó como objetivo una reforma de mínimos que evitara distracciones que ralentizasen la tramitación. También el hecho de que la propia Ley 9/2020 impone la

\footnotetext{
${ }^{36}$ Como último fundamento, en el $\S 11$ Pr. se destaca que en 3.9 del Decreto $1 / 2018$, de 19 de mayo, de creación, denominación y determinación del ámbito de competencia de los departamentos de la Administración de la Generalidad de Cataluña, corresponden al Departamento de Justicia, entre otros (...) la promoción y desarrollo de los medios alternativos de resolución de conflictos». Añadimos, in genere.

${ }^{37}$ Coordinació de Parentalitat noves dates.pdf (última consulta, 11.10.2020)

${ }^{38}$ www.dretcolaboratiu.cat
} 
presentación de un proyecto nuevo de ley [vid. infra apdo. 7] que correlativamente, suponemos, derogará la LMDP.

\section{Una futura -y pronta- ley de prevención, gestión y resolución de conflictos}

La Ley 9/2020, como consecuencia de la Enmienda n.1 de los GP Republicano y Junts per Catalunya -ergo una enmienda de los partidos en el gobierno- impone al gobierno la obligación de "elaborar y presentar al Parlamento un plan sobre la adopción de una política pública de carácter general para la prevención, gestión y resolución extrajudicial de conflictos" (Disposición Tercera) y -lo que nos interesa aquí- la elaboración y presentación, en el plazo de un año, "de un proyecto de ley de prevención, gestión y resolución de conflictos" (Disposición Final Primera). Es una iniciativa que habíamos cuestionado, desde la convicción de que la multiplicación de normas sobre mediación no ha contribuido, hasta la fecha, a consolidar la figura entre los operadores jurídicos. En algún momento hemos llegado a sostener en público que lo que podía resultar efectivo en la práctica no eran más normas, sino forrar autobuses o poner banderolas en las farolas con eslóganes a favor de la mediación (hoy, quizás, una serie en Netflix de una entidad de mediación). De hecho, el § 4 Pr. Ley 9/2020 reconoce que "ni la información disponible en los sitios web, ni los folletos informativos, ni los actos informativos, ni las visitaspersonales a órganos jurisdiccionales han resultado ser prácticas suficientes para motivar a las partes, a los profesionales del derecho y al personal jurisdiccional..." Sin embargo, la reforma hace ahora conveniente, creemos, ese impulso legislativo que antes nos parecía casi superfluo. Por, como poco, tres motivos. 1. Desde una perspectiva estrictamente técnica, porque clarificará algunos de los aspectos que hemos apuntado, y que precisarían de una nueva reforma de mayor calado; 2 . porque la filosofía que subyace en la iniciativa obliga a un marco legislativo nuevo 3. Porque puede ser una manera efectiva de que los abogados, ya más atentos al fenómeno de los ADR desde esta ley, se impliquen definitivamente (aunque ya nos atrevemos a anticipar que una ley de estas características supondrá un proceso de participación particularmente complejo.... $\left.{ }^{39}\right)$.

Al presentar la Ley 9/2020 hemos eludido, conscientemente, un apartado al componente competencial. Nos basta con recordar que se apoya en las competencias en materia civil, las especificidades procesales que se derivan y la competencia en servicios sociales y protección de las familias y los menores (ex $\S 12 \mathrm{Pr}.)^{40}$. Y lo hemos orillado por tres razones: 1 . La simetría de la iniciativa

\footnotetext{
39 Al menos contamos, a día de hoy, con materiales valiosos: las leyes de mediación cántabra (Ley 1/2011, de 28 de marzo (BOE núm. 99, de 26.4.2011) y de la comunidad valenciana (Ley 24/2018, de 5 de diciembre (BOE, núm. 23, de 26.1.2019), que superan las coordenadas del derecho privado y los trabajos de la European Commission for the Efficiency of Justice (CEPEJ), del Consejo de Europa https://www.coe.int/en/web/cepej/cepej-work/mediation

40 "Se dicta al amparo del artículo 129 EAC de Cataluña, según el cual corresponde a la Generalidad la competencia exclusiva en materia de derecho civil, excepto en las materias que el artículo 149.1.8 de la Constitución atribuye en todo caso al Estado. No obstante, la Generalidad puede establecer los instrumentos y los procedimientos de mediación y de conciliación en la resolución de conflictos en las materias de su competencia, le corresponde dictar las normas procesales específicas que deriven de las
} 
con la ley vasca, no cuestionada en ningún momento 2 . El hecho de que ya lo había abordado Ortuño en su comentario dejando claro que "la norma catalana parte el respeto debido a la distribución competencial que establece la Constitución que como es sabido, optó desde el 1978 por encomendar en exclusiva al legislador estatal la legislación procesal"41 3. Un pragmatismo en cuanto a lo que importa ahora. Pero sí queremos hacer un apunte sobre la cuestión competencial en relación con la propuesta de una futura ley de prevención y solución de conflictos para evitar la enésima dialéctica sobre galgos y podencos. Dicha ley no debe leerse desde la dimensión procesal, aunque estemos -obviamente- ante una figura poliédrica que la incluye. Situémonos: los ADR se han construido como herramientas no jurisdiccionales para la resolución de conflictos (a menudo supuestos de la denominada "litigiosidad impropia", esto es, de sesgo no estrictamente jurídico ${ }^{42}$ ). Con esa perspectiva, las CCAA han aprobado leyes de mediación y puesto en marcha servicios de mediación ${ }^{43}$. Cabría pensar que sus iniciativas se circunscribían al ámbito de familia, pero lo desmienten la ley cántabra y la ley valenciana. No se han fundado en un derecho procesal respecto del cual, obviamente no tienen competencias.

Tampoco los procesalistas han tenido un excesivo interés en los ADR, pese a que algunos reputados académicos han escrito excelentes trabajos sobre la materia. Me atrevo a afirmar que entre los profesores de derecho procesal se puede encontrar un paralelismo con la posición de la abogacía: un sector entusiasta y un sector displicente o directamente reacio. Y lo subrayo porque en el futuro, la eclosión de los ADR ligada al covid puede generar una conversión con tintes del entusiasmo constitucionalista de Fernando VII, atribuyendo un protagonismo a la perspectiva procedimental que no se corresponde con la adecuada visión -nos disculpamos por un adjetivo usado en demasía- holística de la figura. No hay una correlación necesaria entre ADR y 'procedimiento-otro'; no es causal que los ADR constituyan en una disciplina autónoma en otros países ( $y$ en otras universidades), porque para su adecuado conocimiento se necesitan competencias específicas. Ciertamente, podemos sostener que la regulación de los ADR se funda en el derecho civil y por tanto, defender su regulación mediante el nexo de la conexión; pero creemos que la formulación va más allá de un título concreto (insistimos en la regulación autonómica, provechosa, de la medición, amparada en otros títulos) o de un título jibarizador. Lo apuntamos queriendo pensar, también, que el legislador catalán es consciente de la mejor manera de

particularidades del derecho sustantivo de Cataluña y dispone, asimismo, de competencias exclusivas en materia de Servicios sociales, protección de menores y promoción de las familias y de la infancia (artículos 106, 130 y 166 del Estatuto de autonomía)". Repite -no podía ser de otro modo- las competencias en que se asientan el CCCat y la LMDP (Pr. §14).

${ }^{41}$ ORTUÑo, "Comentario de urgencia...", op.cit., p.2. El lamenta que "no existan cauces procesales 'ad hoc' para los derechos que reconocen a los ciudadanos las instituciones de derecho civil propio, lo que provoca que no se disponga de una protección eficaz por los tribunales para los mismos. Todos recordamos las famosas acciones del derecho romano que comprendían de forma inseparable el derecho llamado 'sustantivo' y el derecho 'adjetivo' o procesal".

42 Por otro lado, durante años los entusiastas de los ADR han tenido que esforzarse en demostrar que estos instrumentos no conculcaban o aminoraban de ningún modo el derecho a la tutela judicial efectiva. Lo recuerda el propio §5 Pr. Ley 9/2020 con el soporte de la STJUE C-317/2008.

${ }^{43}$ Procura una visión global útil, pese a la existencia de leyes ulteriores, Ma T. DUPLÀ (coord.), El régimen jurídico de la mediación familiar en España. Análisis de la normativa autonómica, Ed. Andavira, Santiago de Compostela, 2012. 
desarrollar sus competencias, instando, si procede, convenios con las instancias del poder judicial, que superen suspicacias sobre injerencias en el ámbito procesal estricto. Y, entonces, junto al esfuerzo legislativo, cobra valor esa obligación de diseñar un Plan sobre políticas públicas en este ámbito.

\section{Una reflexión provisional sucinta}

1. Afirma el magistrado Pascual Ortuño en su imprescindible monografía Justicia sin jueces que "los ciudadanos y las sociedades complejas actuales tienen necesidad de disponer de mecanismos de justicia adecuados para gestionar y resolver sus conflictos cotidianos" y que a día de hoy en muchas ocasiones "se huye del método de confrontación judicial porque en muchas de estas situaciones la eventual victoria ante un tribunal no aportará la solución al problema"44. Esa es la esencia del fenómeno ADR: saber que un buen número de conflictos no se pueden solventar en los juzgados y construir otras herramientas para conseguirlo.

2. La importancia, sin tentaciones de fungibilidad con otras profesiones, de los abogados para consolidar los ADR. Su implicación requiere que los conozcan y se desenvuelvan en ellos con naturalidad (con un training que difiere de la formación para ser mediadores). Esta es una afirmación que no se circunscribe a nuestro entorno (no hace falta recordar, una vez más, el AP de ley de fomento a la mediación del 2018, que previsiblemente se recuperará...) Incluso en EEUU, que parece el país con una consolidación inequívoca de los $A D R$, se hacía notar en un congreso reciente que los abogados seguían conociendo de manera deficiente los ADR ${ }^{45}$.

3. Queda pendiente -y será uno de los mayores retos de los próximos años- fijar indicadores para intuir los ADR adecuados para cada conflicto: esos mecanismos de tría (exitosa) que se están implementando en otros países con medidas que van del checklist entre abogados y clientes a fórmulas de multi-door justice. Una ley de prevención y solución de conflictos puede ayudar.

4. Viendo la iniciativa del legislador catalán, es probable que en un futuro próximo el recurso a los ADR se considere un principio rector del derecho de familia, en la línea, por ej., de la Propuesta de modernización del Derecho de familia del Quebec $(2015)^{46}$, aunque esa era una concepción acorde con la filosofía del país. Baste apuntar que en la reforma de su Code de Procedure (en vigor desde el 2016) se estableció (art. 1) el deber de acudir en primer

\footnotetext{
44 P.ORTuÑo, Justicia sin jueces, Ed. Ariel, Barcelona, 2018, ps. 17 y 21.

45 E.E. Deason, M.Z. Green, D.Shestowsky, R.VAn Loo -E.WALdman, "ADR and Access to Justice: Current Perspectives", Ohio State Journal on Dispute Resolution, vol. 33, n. 3, 2018, p.314.

46 Comité consultatif sur le droit de la famille, A. Roy (dir.), Pour un droit de la famille adapté aux nouvelles réalités conjugales et familiales, Les éditions Thémis, 2015, vid. E.LAUROBA, La Proposition de réforme du droit de la famille québécois vue à travers le prisme des droits catalan et espagnol, Les Éditions Themis.Cahiers du Notariat, pp.64-67. Entre los "principes directeurs de la propuesta aparece la voluntad de "une justice familiale accessible", que se asocia indisolublemente a los ADR.
} 
lugar a las figuras de resolución judicial de conflictos y solo en última instancia a los tribunales ${ }^{47}$.

5. Situar adecuadamente la perspectiva de género en la mediación -y los otros ADR- puede ser un plus para su consolidación. Pero debe asentarse en un trabajo teórico previo riguroso, que en algún momento de lugar a medidas concretas, sobre todo si se identifican déficits reales. Por ejemplo, algunos expertos proponen, como una de las medidas más eficaces para superar dicho sesgo, la comediación ${ }^{48}$, aunque cuenta con la desventaja -no menor- del incremento de costes; países como Austria la han convertido en modalidad preferente y en base a la perspectiva de género estiman que debería procurase que los equipos fueran mixtos: un mediador y una mediadora ${ }^{49}$. Ahora bien, quizás en nuestro país esta propuesta obligue a una reflexión diferente, pues en el ámbito familiar el número de mediadoras es notablemente superior al de mediadores, también recordar que no todas las parejas incorporan dualidad de géneros, incluso que empiezan a detectarse familias más allá de lo binario... Valdrá la pena reflexionar sobre ello con rigor para evitar tentaciones tertulianas.

6. Como tanto la administración como la sociedad se rigen por la ley del péndulo -o, con mayor corrección, por la tríada dialéctica-, es posible que se abra un debate sobre la oportunidad de incrementar el número de horas de formación -que, debidamente homologadas, permite formar parte de los registros públicos de mediación-. En Cataluña hoy es 170 y las formaciones suelen adaptarse a esos parámetros, aunque inicialmente eran superiores, pero hubo un consenso -implícito- en no fijar coordenadas demasiado alejadas de las 100 horas que fija el Reglamento de la LMACM. Dicho esto, baste apuntar que frente a quienes sostienen que incluso 100 horas son excesivas, amparándose en el modelo americano (como extensión standard 40), que los propios americanos están cuestionando la calidad de su formación, por reducida. Aunque no sería tan importante ese formato, al menos en términos de duración, si ya se hubiera introducido formación en ADR en los grados universitarios.

7. La Ley 9/2020 deja intuir una inteligente transformación del Centro de Mediación si va acompañada de un protagonismo real -esto es, efectivo y eficiente-. Si los propios Departamentos de la Generalitat son capaces de

\footnotetext{
${ }^{47}$ Así, el $\S 1.3$ establece: "Les parties doivent considérer le recours aux modes privés de prévention et de règlement de lleur différend avant de s'adresser aux tribunaux 》.

48 Por todos, IZUMI, "Implicit Bias...", op.cit., p. 692

${ }^{49}$ M.Martin Casals, "La comediación como modelo", en E.LAuroba-I.Barral-I.Viola (dirs.), Materiales jurídicos del Libro Blanco de la Mediación en Cataluña, Generalitat de Catalunya, CEJFE, Barcelona, 2011, pág. 185, explica las Directrices austríacas para la promoción de la mediación (2004) -complemento indisoluble de su ley de mediación del 2003- y la atención a dicha perspectiva. El analiza sus ventajas (pps. 187-191): a) Refuerza la figura; b) Posibilita una dinámica más estable del proceso; c) Permite adaptar mejor la mediación a las características de las partes -esa perspectiva de género: d) Permite a los comediadores complementarse profesionalmente; e) Permite la división del trabajo; f) Permite llevar a término reuniones de análisis e intercambio de información entre los comediadores; g) Permite una mejor gestión de situaciones con fuerte carga emocional; h) permite que la actuación de los comediadores pueda servir de modelo a la conducta de las partes.
} 
desarrollar políticas cooperativas y no competitivas -la filosofía que subyace en los ADR-, el Centro puede convertirse en repositorio de la información (real) de las experiencias en mediación que coexisten al amparo de la administración catalana, desde la mediación escolar a la de cooperativas o del consumo -por identificar tres modalidades que cuentan con amparo normativo ${ }^{50}$, sin olvidar otras en el ámbito de los conflictos comunitarios (de la vivienda al espacio público). Eso requiere más medios y despejar desconfianzas, tanto con los colegios profesionales como con el poder judicial; también saber acotar los ámbitos de intervención (esto es, saber excluirse de lo que no le es propio) y conseguir impulsar iniciativas sorprendentes -en lenguaje grato a la UE, disruptives-.

8. Y una última reflexión, desde mi preocupación in crescendo ante entusiasmos acríticos hacia los ADR, que la nueva situación amplifica. No son una panacea, sino un instrumento de utilidad probada que entiende cooperar como estrategia ${ }^{51}$. Hay que deslindarlos tanto de las tentaciones asociadas a aminorar la partida presupuestaria de justicia -tentación que subyace casi siempre ${ }^{52}$ - como de referencias naifs a una cultura de la paz convertidas en lugares comunes. En los últimos años, hemos constatado que toda charla de un mediador/a que se precie se salpimienta con alguna frase célebre para apuntalar las bondades y excelencia ética de la mediación. Esa visión impregna también demasiadas formaciones. Pero del mismo modo que André Gide afirmaba que "No se hace buena literatura con buenas intenciones", los ADR no se desarrollarán enfatizando las virtudes del hombre en el estado de naturaleza de Rousseau. La clave es la conjunción de generación y absorción de conocimiento riguroso, multiplicación de medios, evaluación de experiencias y festina lente. Dicho esto, y puesto que hemos ironizado sobre el excesivo recurso a frases ajenas, concluimos, como contrición, con una frase de F.J.Kennedy que resume el empeño -aquí del legislador catalán- para la mejor consolidación del ecosistema ADR: "Elegimos ir a la luna no porque sea fácil, sino porque es difícil".

\footnotetext{
${ }^{50}$ Vid., todavía útiles, E.CASAÑAS, "El Decreto 279/2006: La mediación escolar como proceso educativo de gestión de conflictos" y M-P. VidAL-Foch-E.SAltor, F.ReCASEns, C.Chacón y E.MARTínez, "Los procedimientos de mediación en empresas de economía cooperativa", en E.LAUROBA-I.BARRAL-I.VIOLA (dirs.), Materiales jurídicos del Libro Blanco de la Mediación en Cataluña, Generalitat de Catalunya, CEJFE, Barcelona, 2011, pp. 57-68 y 69-82 respectivamente. En relación con el derecho al consumo, el capítulo en el LBMC sobfe mediación en consumo que I.BARRAL, así como I.BARRAL (ed.), La resolución de conflictos con consumidores de la mediación a las ODR, Ed. Reus, Madrid, 2018 e I.BARRAL (dir.), Viola DemeStreV.PÉREZ DAUDí (coords.), El sistema de ADR/ODR en conflictos de consumo: aproximación crítica y prospección de futuro, Atelier, Barcelona, 2019.

51 También imprescindible, siempre, P.FAJARDO, Cooperar como estrategia. Mediación de conflictos empresariales, Thomson Reuters Aranzadi, Cizur Menor, 2016.

52 Lo recordaba S.BARONA, "Integración de la mediación en el moderno concepto de Acces to Justice. Luces y sombras en Europa", InDret, 4/2014, p. 27, al señalar que estábamos en un momento de diseño de la justicia del siglo XXI.
} 